\title{
BIOSYNTHESIS OF THE PROTOBERBERINE ALKALOID JATRORRHIZINE
}

M. Rueffer, O. Ekundayo, N. Nagakura ${ }^{+}$, and M.H. Zenk

Lehrstuhl Pharmazeutische Biologie, Universität München, 8000 München 2, W-Germany

'Kobe Women's College of Pharmacy, Kobe 658, Japan

Abstract: Feeding experiments with distant single or doubly labelled precursors show that the methylene dioxy group of berberine is opened in the formation of jatrorrhizine.

Jatrorrhizine, the major alkaloid of Berberis cell cultures ${ }^{1}$, contains an unusual 2-0-methylation pattern which makes it difficult to deduce its biosynthesis from reticuline, the common precursor of isoquinoline alkaloids. A recent publication ${ }^{2}$ prompts us to present here some of our work on this topic. Partially purified norlaudanosoline-6-0-methyltransferase from Papaveraceae cell cultures catalyses the formation of 6-0-methylnorlaudanosoline $\left(R_{1}=\right.$ Me; $\left.R_{2}-R_{5}=H\right)$ along with a smaller amount of 7-0-methylnorlaudanosoline $\left(R_{2}=\right.$ Me; $\left.R_{1}=R_{3}-R_{5}=H\right)$ exactly like the mammalian catechol-0-methyltransferase ${ }^{3}$. Therefore, the possibility existed that the 2-0-methylation pattern of jatrorrhizine is established already at the norlaudanosoline level. Further methylation reactions, cyclisation and oxidation could lead to jatrorrhizine via protosinomenine (IV), which should be a good substrate for the cyclising berberine-bridge enzyme 4 .

In order to test this possibility, (S)-reticuline (III, $-\mathrm{N}-{ }^{14} \mathrm{CH}_{3}$ ) and (S)-protosinomenine ( IV, $-\mathrm{N}^{14} \mathrm{CH}_{3}$ ) were fed to callus of Berberis stolonifera ${ }^{1}$. A predominant incorporation of (S)-reticuline (4.4\%) over (S)-protosinomenine $(0.73 \%)$ into jatrorrhizine was observed, indicating a preference for the reticuline pathway. To study even more distant precursors (R,S)6-0-Melaudanosoline (I) and its 7-0-Me isomer (II) were synthetized with a $-\mathrm{N}_{-}{ }^{14} \mathrm{CH}_{3}$ label and applied to callus. Again, derivative I, with the methyl group in the "wrong" position, showed better (4\%) incorporation than the 7-0-Me isomer $(0.6 \%)$. Reduction of the labelled jatrorrhizine with $\mathrm{BH}_{4}^{-}$followed by demethylation ${ }^{5}$ showed that no transfer of label to the methoxyl groups had occurred. These results indicate that transformation of precursors I and III into jatrorrhizine must involve an internal transfer of the methyl group from the c-6-position in (S)reticuline to the c-2-position in jatrorrhizine.

To provide experimental proof for this intramolecular methyl transfer doubly labelled precursor I was prepared using purified enzymes and S-adenosyl- 
[methy $1-{ }^{3} \mathrm{H}$ ]- and [methy $1-{ }^{14} \mathrm{C}$ ]-methionine to label the $6-0$ - and the $\mathrm{N}$-methyl groups respectively (Scheme 1 ). This compound $\left(1.5 \mathrm{nmol} ; 6.78 \times 10^{5} \mathrm{dpm}^{3} \mathrm{H}\right.$; $\left.2.05 \times 10^{5} \mathrm{dpm}^{14} \mathrm{C} ;{ }^{3} \mathrm{H}:{ }^{14} \mathrm{C}=3.3: 1\right)$ was supplied to $1 \mathrm{~g}$ B. stolonifera callus and allowed to metabolize for $48 \mathrm{~h}\left(23^{\circ} \mathrm{C}\right)$. Incorporation into jatrorrhizine was $0.6 \%\left({ }^{3} \mathrm{H}:{ }^{14} \mathrm{C}=2.1: 1\right)$. This isotope ratio corresponds exactly to a loss of $1 / 3$ of the tritium label in the original 6-0- $\mathrm{CH}_{3}$ of I. Berberine, which was also isolated from this callus showed $0.6 \%$ incorporation of I and the same isotope ratio $\left({ }^{3} \mathrm{H}:{ }^{14} \mathrm{C}=2.2\right)$ as found in jatrorrhizine. This finding suggested that jatrorrhizine is formed from berberine by reopening of the methylene dioxy group. Indeed, berberine- ${ }^{14} \mathrm{C}$ (produced from L-tyrosine-2-14 by Thalictrum minus callus) was incorporated to an extent of $1.6 \%$ into jatrorrhizine $(24 \mathrm{~h}$ feeding). These experiments provide proof that the major biosynthetic route to jatrorrhizine is through berberine (Scheme 1). A minor route can be envisaged through (S)-protosinomenine which already carries the methoxy group in the "correct" 7-position.

The precursor role of berberine is in absolute agreement with the demonstration by Beecher and Kelleher ${ }^{2}$ of the in vivo transformation of berberine (9-0- $\left.{ }^{14} \mathrm{CH}_{3}\right)$ into jatrorrhizine. We fully agree with their proposed mechanism for the conversion of berberine into jatrorrhizine.<smiles>[R20]Oc1ccc(C[C@H]2c3cc(O[R20])c(O[R20])cc3CCN2[R5])cc1O[R6]</smiles><smiles>[3H]C([3H])([3H])Oc1cc2c(cc1O)C(Cc1ccc(O)c(O)c1)N([14CH3])CC2</smiles>

6-O-METHYL-LAUDANOSOLINE (I) ISOTOPE RATIO: $\left(T:{ }^{14} \mathrm{C}=3.3: 1\right)$

\section{$1 \quad R_{1}=R_{5}=M e ; R_{2}=R_{3}=R_{4}=H(6-0-M E T H Y L-L A U D A N O S O L I N E)$ \\ II $R_{2}=R_{5}=M e ; R_{1}=R_{3}=R_{4}=H$ (7-O-METHYL-LAUDANOSOLINE) \\ III $R_{3}=R_{4}=R_{5}=M e ; R_{2}=R_{3}=H$ (RETICULINE) \\ IV $R_{2}=R_{4}=R_{5}=M e: R_{1}=R_{3}=H$ (PROTOSINOMENINE)}

Acknowledgement: Supported by SFB 145 of Deutsche Forschungsgemeinschaft, Bonn.

\section{References:}

1. Hinz, H., and M.H. Zenk. Naturwiss. 67, 620 (1981).

2. Beecher, C.W.W., and W.J. Kelleher. Tetrahedron Lett. 24, 469 (1983).

3. Meyerson, L.R., J.L. Cashaw, K.D. McMurtrey, and V.E. Davis. Biochem.Pharmaco1. 28, 1745 (1979).

4. Böhm, , H., and E. Rink. Biochem.Physiol.Pflanzen 168, 69 (1975).

5. Späth, E., and R. Posega. Berichte 62, 1029 (1929).

(Received in Germany 30 March 1983) 